\title{
Hyalinizing Clear Cell Salivary Gland Carcinoma of the Epipharynx: A Minor Salivary/Tubarial Gland Malignancy
}

\author{
Hannes Hermann Brandt ${ }^{\mathrm{a}} \quad$ Daniel Baumhoer ${ }^{\mathrm{b}} \quad$ Nora Tetter $^{\mathrm{a}}$ \\ ${ }^{a}$ Department of Otolaryngology, Kantonsspital Aarau AG, Aarau, Switzerland; ${ }^{b}$ Bone Tumor Reference Centre, \\ Institute of Medical Genetics and Pathology, University Hospital Basel, University of Basel, Basel, Switzerland
}

\section{Established Facts}

- Minor salivary gland malignancies are rare; their histological subtypes are numerous.

- Differentiation on histological review may present a challenge to the pathologist involved.

- Epipharyngeal lesions with a benign aspect on clinical examination, invariably warrant histological analysis.

\section{Novel Insights}

- FISH-analysis should be considered the next diagnostic step in a tumor demonstrating clear cell morphology - when an EWSR1-ATF1 fusion is found, the diagnosis of hyalinizing clear cell carcinoma can be made.

- The tumor described here, fits the location of the newly proposed - yet still heavily debated - "Tubarial Gland."

\section{Keywords}

Hyalinizing clear cell carcinoma · Epipharyngeal malignancy · EWSR1-ATF1 fusion · Head and neck malignancy $\cdot$ Tubarial glands

\section{Abstract \\ Minor salivary gland malignancies are a rare entity among head and neck tumors. As in major gland neoplasms, ade- noid cystic carcinoma and mucoepidermoid carcinoma are the most common histological subtypes. Malignant tumors affecting minor salivary glands include a wide range of his- topathologic types. Localization in the epipharynx and hya-}

linizing clear cell carcinoma subtype are exceedingly rare. A 47 year-old male presented to our clinic with a complaint of slowly progressing left-sided nasal obstruction. Endoscopy revealed a well-defined nodular epipharyngeal mass. Radiographic evaluation discovered a nonvascularized tumor of the tubal protuberance. The tumor was treated with wide local excision. Staging at the time found no evidence of regional lymph node metastases. Histologic examination revealed a hyalinizing clear cell salivary gland carcinoma demonstrating an EWSR1-ATF1 gene fusion. Restaging endoscopy and radiographic imaging 3 months after initial therapy did not reveal any signs of tumor persistence. The patient is currently in follow-up.

(C) 2022 The Author(s)

Published by S. Karger AG, Basel
C 2022 The Author(s).

Published by S. Karger AG, Basel

This article is licensed under the Creative Commons Attribution 4.0 International License (CC BY) (http://www.karger.com/Services/ OpenAccessLicense). Usage, derivative works and distribution are permitted provided that proper credit is given to the author and the original publisher.
Correspondence to:

Daniel Baumhoer, daniel.baumhoer@usb.ch 


\section{Introduction}

Nasal obstruction is a frequent reason for consulting an ENT specialist. Septal deviation, conchal hyperplasia, or rhinosinusitis are frequently encountered in this setting. Nasal endoscopy, which is mandatory in the workup of obstructive symptoms, rarely reveals a epipharyngeal mass.

In adults, a unilateral symptomatic mass invariably indicates epipharyngoscopy and biopsy to rule out malignancy. While epipharyngeal squamous cell carcinoma is the most frequently encountered cancer in this location, other tissues may also show malignant transformation. In our case, a rare salivary gland malignoma was discovered in a patient with slowly progressing nasal obstruction.

Our purpose is to sensitize the reader to different histologic subtypes of epipharyngeal malignancies. We would also like to demonstrate the histologic workup of a salivary gland tumor that required multiple stains and molecular analysis to reach a definitive diagnosis.

\section{Case Report}

A 47 year-old male patient was referred to our clinic by his family doctor with a complaint of left-sided nasal obstruction which he first noticed about 3 years back. Symptoms had been progressing ever since, however, no other complaints were reported.

The patient's past medical history included type II diabetes, hypertension, asthma, and obstructive sleep apnea syndrome. Rhinoscopy ruled out deviation of the nasal septum or inferior turbinate hypertrophy. Nasal endoscopy revealed a well-defined nodular mass of about $2 \mathrm{~cm}$ in diameter with intact mucosal lining originating from the dorsal torus tubarius and salpingopharyngeal fold.

The tumor did not show any signs of excessive vascularity or infiltration in an MRI (shown in Fig. 1). A CT scan did not demonstrate erosions of osseous structures or cervical lymphadenopathy. Epipharyngoscopy with diagnostic excision was performed (shown in Fig. 2, 3). Histologic workup revealed an infiltrative epithelial tumor growing in solid sheets and cords, glandular structures were absent (Fig. 4). The cytoplasm was predominantly pale-eosinophilic but also showed areas with prominent clear cell change. Overall, the tumor cells appeared monomorphic and lacked high-grade atypia and mitotic figures, stromal hyalinization was marked. Immunohistochemically, the tumor cells were consistently positive for p63 and p40 and mostly positive for
Fig. 1. Axial CT and MRI demonstrate a round, well-defined structure with seemingly no infiltration of the surrounding structures.

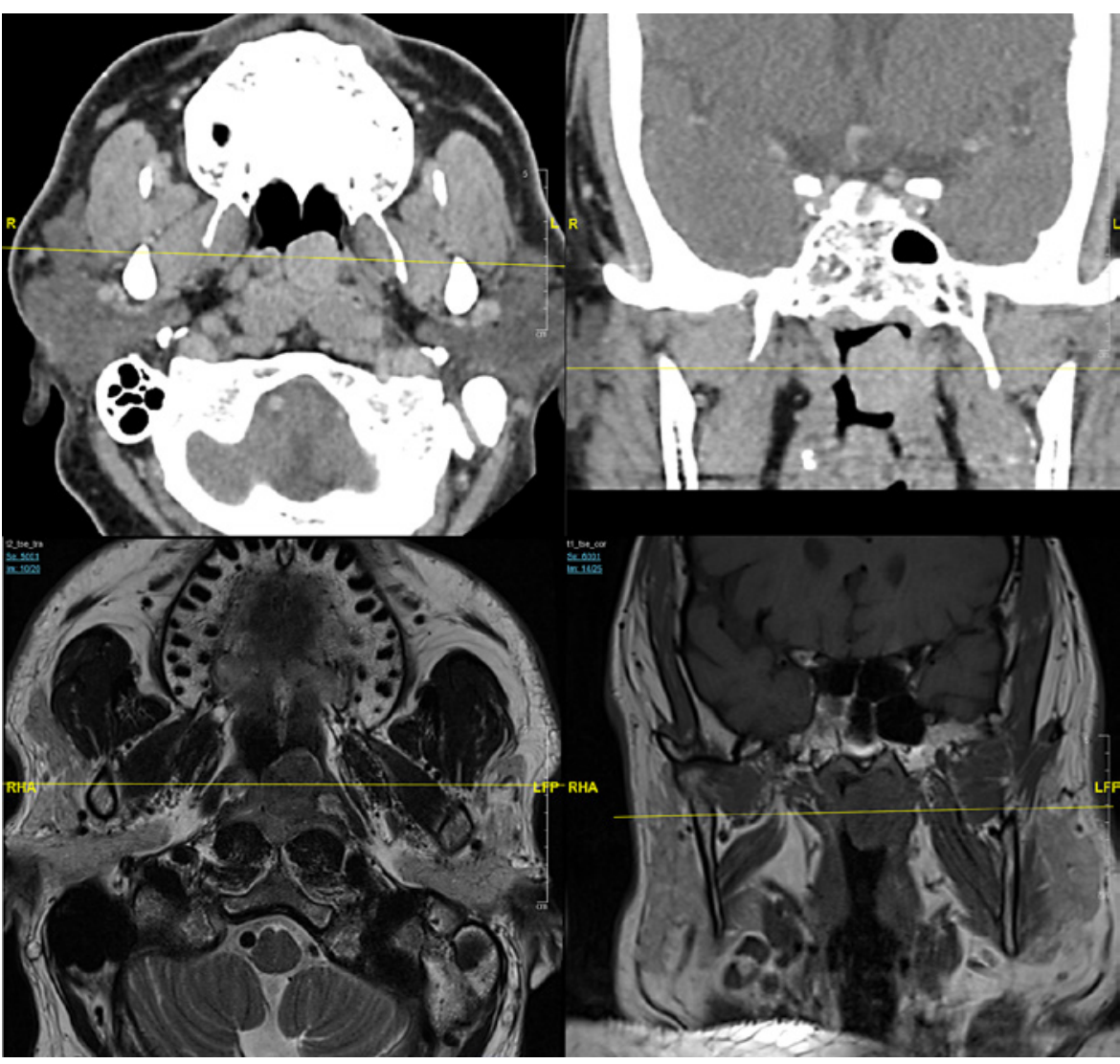


CK5/6 and CK7. HPV and EBV association was ruled out (negative p16 immunostain and EBER ISH), CD117, SMA, and S100 turned out negative as well. The proliferation index (MIB1) was around 5\%. Due to the clear cell change of the tumor cells, a EWSR1 FISH was carried out and revealed a gene rearrangement (Fig. 5); RNA sequencing subsequently identified an EWSR1ATF1 fusion transcript. As a consequence, the diagnosis of a hyalinizing clear cell carcinoma (pT1) originating from a minor epipharyngeal salivary gland was made. The patient subsequently underwent wide local excision, which demonstrated negative margins.

After discussion in our interdisciplinary tumor board, no adjuvant therapy was recommended. The patient did not show any signs of persistent disease in a restaging endoscopy with biopsy and MRI of the neck performed 3 months after initial resection. $\mathrm{He}$ is currently receiving regular follow-up in our clinic and has been disease free for a year now.

\section{Discussion}

Primary epipharyngeal malignancies mostly arise from the mucosal lining of the epipharynx. They account for $5 \%$ of head and neck malignancies [1]. Salivary gland tumors constitute around $8 \%$ of all head and neck cancers, and the prevalence of individual tumor subtypes differs between the major and minor salivary glands [2].

Minor salivary gland malignancies are tumors that can arise anywhere in the upper aerodigestive tract, due to the ubiquitous distribution of submucous minor salivary glands in this area. They are also rare among head and neck tumors, accounting for around $10-15 \%$ of all salivary gland tumors and therefore for about $1 \%$ of all head and neck cancers [3-5].

Fig. 2. Epipharyngoscopy reveals the round mass in the left epipharynx $(*)$. For better orientation, the tubal protuberance on the right $\left({ }^{\mathrm{x}}\right)$ and the dorsal border of the nasal septum $(\#)$ are marked accordingly.

Fig. 3. After resection of the tumor at its base, it is evident that it arose from the dorsal tubal protuberance.

2

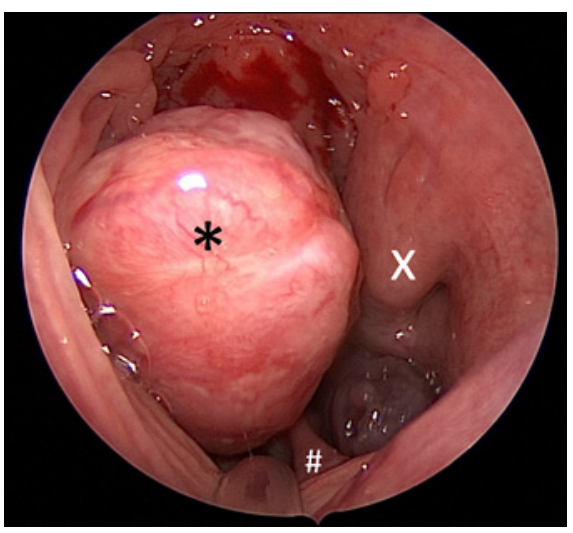

3

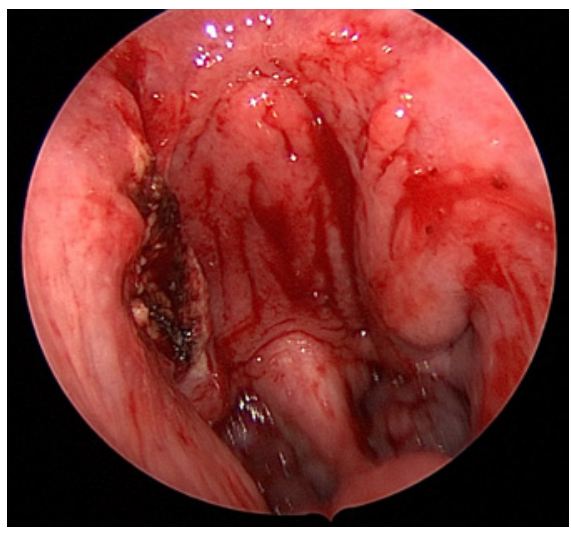

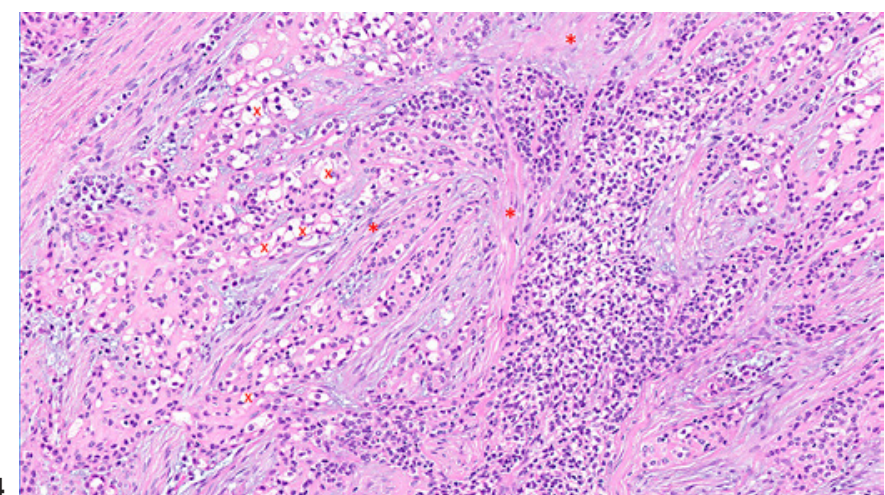

Fig. 4. Histology shows epithelial cells $\left({ }^{\mathrm{x}}\right)$ arranged in cords and trabeculae with a partly clear cytoplasm and surrounded by a hyalinized stroma $(*)$.

Fig. 5. EWSR1 FISH shows break apart hybridization signals. The shown areas with red and green signals demonstrate separate detection of the red and green probe of the EWSR1 gene. When the EWSR1 gene is intact, a yellow signal is expected.

Hyalinizing Clear Cell Salivary Gland

Carcinoma of the Epipharynx

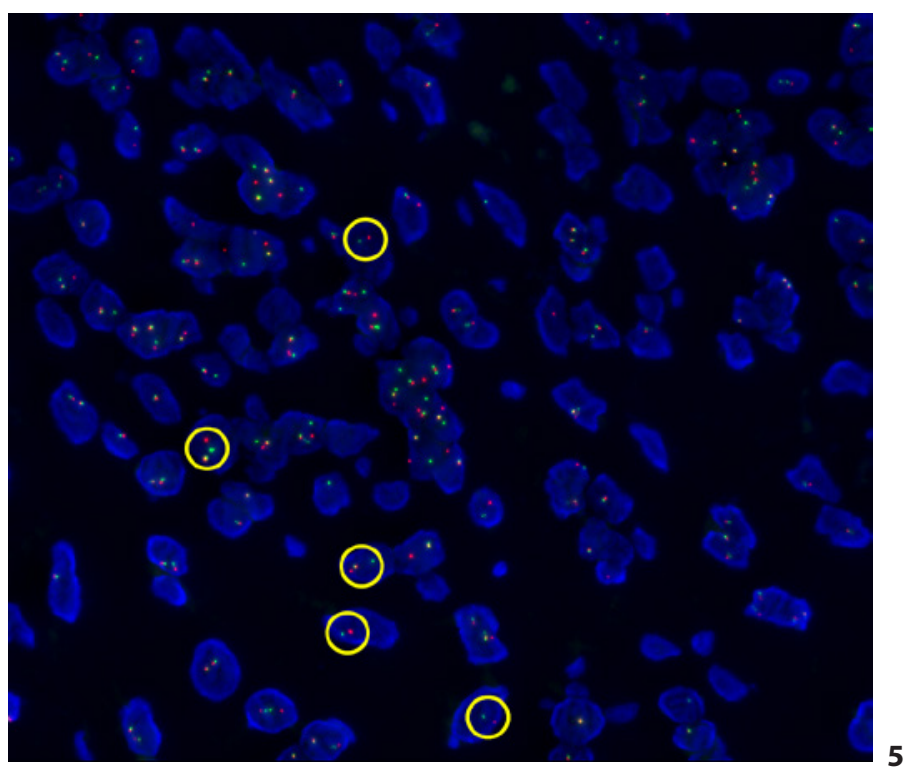

Biomed Hub 2022;7:31-35 
The parotid is the site of most benign and malignant salivary neoplasms, benign tumors being far more prevalent [3]. Minor salivary gland neoplasms, however, are more likely to be malignant [6]. The most common localization of minor salivary gland malignancies is the soft palate [5]. Mucoepidermoid carcinoma (MEC) is the most common histologic entity, followed by adenoid cystic carcinoma $[5,6]$. Epipharyngeal minor salivary gland malignancies are exceedingly rare. While Schramm and Imola [7] report a total of 98 cases in a review of the English literature in 2001, a case series of 450 cases of minor salivary gland malignancies from Hay et al. [5] from 2019 did not describe a single case located in the epipharynx.

One of the rarest subtypes encountered in all salivary gland malignancies is hyalinizing clear cell carcinoma. It was first described by Milchgrub et al. [8]. A review from 2014 lists a total of 161 cases in the literature - only 7 of which were localized in the epipharynx [9]. Due to the diversity of histopathologic features, classification of salivary gland tumors is complex and therefore challenging. Histological mimics also containing clear cells include MEC, epithelial-myoepithelial carcinoma, and myoepithelial carcinoma, respectively. In contrast to hyalinizing clear cell carcinoma, MEC commonly shows cystic change and the characteristic mixture of epidermoid and intermediate cells as well as mucocytes. Furthermore, CRTC1MAML2 represents a molecular marker for MEC. Epithelial-myoepithelial carcinoma on the other hand generally displays prominent ductal structures and spindled patterns, which are rare in hyalinizing clear cell carcinoma. Lastly, perineural invasion, mucosal involvement, and mucin formation are common features of hyalinizing clear cell carcinoma but usually not seen in myoepithelial carcinoma [10]. A crucial discovery in the diagnosis of hyalinizing clear cell carcinoma, however, was the consistent discovery of EWSR1-ATF1 gene fusions, which can aid in the differential diagnosis [11].

As for many rare pathologies, no consensus papers or guidelines exist for treatment standards. Yet, treatment of choice in hyalinizing clear cell carcinoma of the head and neck seems to be wide local excision - accompanied by neck dissection when nodal invasions are likely in diagnostic staging $[8,12,13]$. Adjuvant radiotherapy was widely indicated in several reported case series, especially when no negative margins could be achieved during surgery $[8,12-15]$.

Primary radiotherapy has been discussed for tumors not accessible to a surgical approach, e.g., in the base of the tongue [10]. Chemotherapy seems to play a minor role in the treatment plans administered $[12,13]$.
Two different cases series have noted lymph node metastasis on presentation in $12 \%$ and $18 \%$ of cases, respectively $[8,13]$. Evidence of necrosis within the tumor seems to be associated with a high risk for recurrence $(80 \%$ vs. $16 \%$ in non-necrotic tumors) [13]. Locoregional recurrence is reported at $12-17 \%[11,12]$. Overall prognosis seems favorable, a large case series giving a mortality of under $4 \%$ in over 80 cases [13]. Like with most malignancies, regular follow-up is indicated to detect recurrent disease and take appropriate actions.

As far as the location of the tumor in our case is concerned, researchers from the Netherlands have recently published the discovery of a new salivary gland located on the area of the torus tubarius - the so-called Tubarial Glands [16]. This would correspond to the location of the malignancy in the presented case, although not all specialists agree that this in fact a newly discovered organ [17].

\section{Conclusion}

Hyalinizing clear cell carcinoma of the minor salivary glands located in the epipharynx is an exceptionally rare diagnosis in the workup of a epipharyngeal mass. The histopathologic diversity renders the classification of salivary gland tumors complicated. A breakthrough discovery in 2011 was the consistent finding of underlying EWSR1-ATF1 fusion transcripts in this malignancy. An EWSR1 FISH should therefore be considered if a hyalinizing clear cell carcinoma is suspected.

\section{Statement of Ethics}

Written informed consent was obtained from the patient directly for publication of the details of their medical case and the accompanying images. Since the patient's case was worked up in a retrospective manner and no additional or otherwise unnecessary measures were undertaken, the paper is exempt from ethical committee approval in Switzerland.

\section{Conflict of Interest Statement}

The authors have no conflicts of interest to declare.

\section{Funding Sources}

This project was not funded in any way.
Brandt/Baumhoer/Tetter 


\section{Author Contributions}

H.H.B. and N.T. were the team initially operating on the patient. D.B. was the pathologist who made the diagnosis after applying mentioned molecular biologic techniques. H.H.B. prepared the first manuscript which was then thoroughly reviewed, corrected, and enhanced by both N.T. and D.B.

\section{Data Availability Statement}

The data that support the findings of this study are available on request from the first author (H.H.B.). The data are not publicly available due to matters concerning the patient's privacy.

\section{References}

1 Chen YP, Chan ATC, Le QT, Blanchard P, Sun Y, Ma J. Nasopharyngeal carcinoma. Lancet. 2019;394:64-80.

2 Lobo R, Hawk J, Srinivasan A. A review of salivary gland malignancies: common histologic types, anatomic considerations, and imaging strategies. Neuroimaging Clin N Am. 2018; 28:171-82.

3 Guzzo M, Locati LD, Prott FJ, Gatta G, McGurk M, Licitra L. Major and minor salivary gland tumors. Crit Rev Oncol Hematol. 2010; 74:134-48.

4 Vander Poorten V, Hunt J, Bradley PJ, Haigentz M Jr, Rinaldo A, Mendenhall WM, et al. Recent trends in the management of minor salivary gland carcinoma. Head Neck. 2014;36:444-55.

5 Hay AJ, Migliacci J, Karassawa Zanoni D, McGill M, Patel S, Ganly I. Minor salivary gland tumors of the head and neck-memorial sloan kettering experience: incidence and outcomes by site and histological type. Cancer. 2019; 125:3354-66.
6 Bradley PJ, McGurk M. Incidence of salivary gland neoplasms in a defined UK population. Br J Oral Maxillofac Surg. 2013;51:399-403.

7 Schramm VL, Imola MJ. Management of nasopharyngeal salivary gland malignancy. Laryngoscope. 2001;111:1533-44.

8 Milchgrub S, Gnepp DR, Vuitch F, Delgado R, Albores-Saavedra J. Hyalinizing clear cell carcinoma of salivary gland. Am J Surg Pathol. 1994;18:74-82.

9 Ceballos Sáenz C, Argyris PP, Manivel JC, Urias Barreras CM, Koutlas IG. Nasopharyngeal hyalinizing clear cell carcinoma: report of the histopathologic features of a case showing EWSR1 rearrangements by FISH and literature review. Int J Surg Pathol. 2014;22:66772.

10 Weinreb I. Hyalinizing clear cell carcinoma of salivary gland: a review and update. Head Neck Pathol. 2013;7 Suppl 1(Suppl 1):S20-9.

11 Antonescu CR, Katabi N, Zhang L, Sung YS, Seethala RR, Jordan RC, et al. EWSR1-ATF1 fusion is a novel and consistent finding in hyalinizing clear-cell carcinoma of salivary gland. Genes Chromosomes Cancer. 2011;50: 559-70.
12 Solar AA, Schmidt BL, Jordan RC. Hyalinizing clear cell carcinoma: case series and comprehensive review of the literature. Cancer. 2009;115:75-83.

13 Albergotti WG, Bilodeau EA, Byrd JK, Mims MM, Lee S, Kim S. Hyalinizing clear cell carcinoma of the head and neck: case series and update. Head Neck. 2016;38:426-33.

14 Pujary K, Rangarajan S, Nayak DR, Balakrishnan R, Ramakrishnan V. Hyalinizing clear cell carcinoma of the base of tongue. Int $J$ Oral Maxillofac Surg. 2008;37:93-6.

15 O'Regan E, Shandilya M, Gnepp DR, Timon C, Toner M. Hyalinizing clear cell carcinoma of salivary gland: an aggressive variant. Oral Oncol. 2004;40:348-52.

16 Valstar MH, de Bakker BS, Steenbakkers RJHM, de Jong KH, Smit LA, Klein Nulent TJW, et al. The tubarial salivary glands: a potential new organ at risk for radiotherapy. Radiother Oncol. 2021;154:292-98.

17 Guntinas-Lichius O, Ihrler S, Freesmeyer M, Gühne F, Kluge R, Bräuer L, et al. [Is there a new salivary gland?: rather not!]. Laryngorhinootologie. 2021;100(1):12-4. German. 